\title{
Visual Literacy: A Bet to Be Earned, ASAP
}

\author{
Sachpatzidis D. Avraam
}

I. T Teacher, Department of Fine Arts, School of Film, Aristotle University of Thessaloniki, Greece

\section{ARTICLE INFO}

\section{Keywords: \\ Communication}

Design

Educator

Image

Internet

\begin{abstract}
New language produces new thought. creativity, critical thinking, educational achievement, empathy towards others, and ability to decipher technology. The gap between looking and seeing can be bridged with observing- the process of building a catalogue of visual elements, a very important argument in front of the so called "narrowness of the education system."

The science of perception and the history of image through the ideas of Eratosthenes, Copernicus, Descartes, Aristotle, Confucius and many others, is to create meaning. Language is, and always will be, the ultimate form of communication.

A book of illustrations and not with illustrations, could make complex arguments through that medium that he couldn't with words alone. Words have been considered for many centuries of the human history, the superior currency of intellect. So, educators don't know where to start when it comes to teaching visual literacy.

Photos without captions can make us look only at the photo, and make judgments and inferences by ourselves. Teaching graphic design alongside poetry, could show that design it's more than just lines and illustration. It a sophisticated way to grasp the procedure from an idea to a picture.

The sooner teachers can really abandon the Learning Styles Theory and not label students as "visual learners", since we all learn visually, the sooner students will be empowered to become visually literate. Not all serious ideas require words, and many are better off without them. Visual communication deserves its place, and can also serve education.
\end{abstract}

\section{Introduction}

According to the poet Simonides, "Words are the images of things" (as cited in Benson, 1997 p. 141); similarly, Aristotle stated that, "without image, thinking is impossible" (as cited in Benson, 1997, p. 141). The education's continuing mission and objective is to meet the needs of learners, doing so through the long-standing process of reading, writing, counting, and memorizing texts. The skills that have to be presented for the clerk in the past decade, are giving their way to skills of analysis and innovation, synthesis and management of big data, making sense of a huge amount of information of unknown source in today's modern cultures (West, 1997).

Even Socrates portrayed the new technology of the written word as something dangerous and destructive, artificial and rigid. Following change with fear and skepticism often accompanies shifts such as these that can revolutionize society. So, it is not a bet or challenge, but a reality to be faced and managed. 


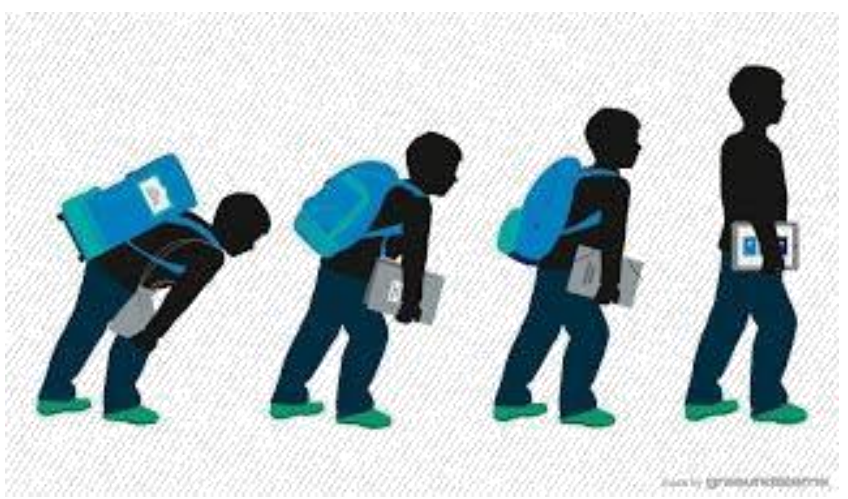

Figure 1. The evolution of learner (Source: Internet Search)

\section{Technology and Education: a non-stop discussion}

In the Report of UNESCO on world education (OECP, 1990) are mentioned three fundamental matters for the use of computers in developed countries. These are 1) computers are tools for the acquisition of basic knowledge and skills that concern information technology, 2) they support the curriculum vitae and 3) they facilitate human interactions between teacher and learner during the training process.

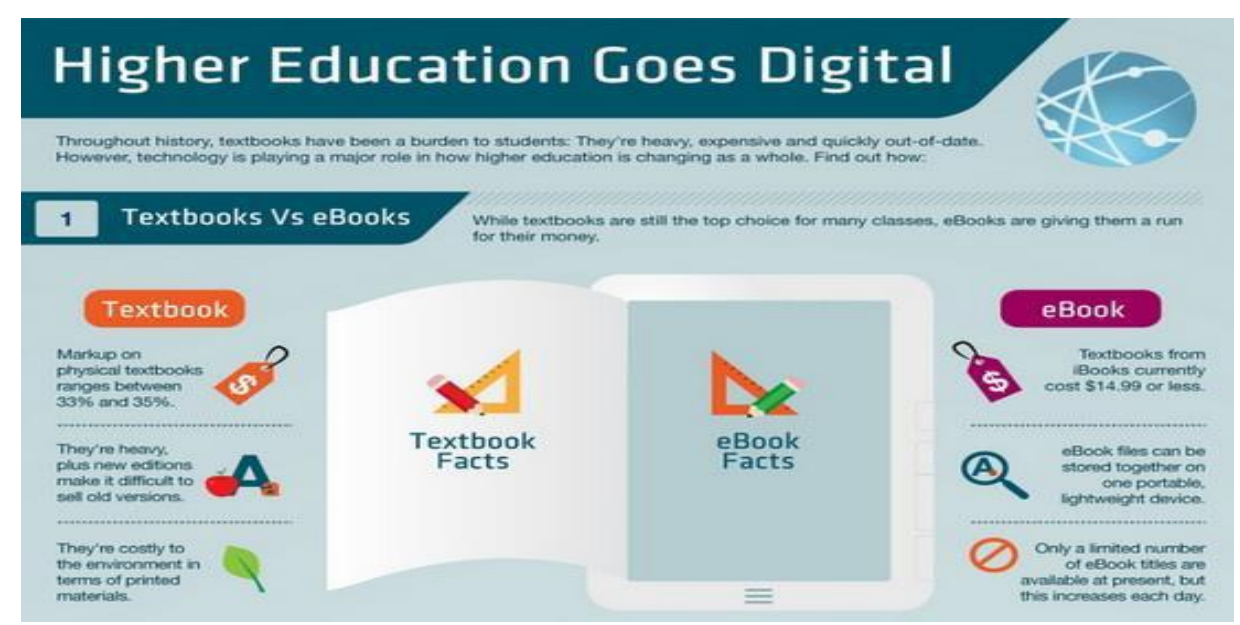

Figure 2. The digital era of education (Source: Internet Search)

As far as history concerns Papert's (1991) view that technology "will cause a revolution in the way of thinking and learning of human beings". He also mentioned that the fact that its fast and multilevel make it penetrate in all areas of human activities. This evidently led to the conclusion that information technology constitutes a substantial and essential part of modern life.

Besides, it has been mentioned that "information technology sector shows a rapid increase and it is estimated that at the end of the 20th century $60 \%$ of jobs will need the use of computer technology skills" (Hawkins \& Blakeslee, 1996).

The use of ITC in education, in well-organized schools, and almost in all public and private schools around the world, has positive effects on the academic performance of students because increases their desire for learning and enhances their positive attitude towards education (US Congress, Office of Technology Assessment, 1988).

On the other hand, older pedagogical views and concerns regarding ways to form the most appropriate learning and development systems, seem to converge, to the admittance that the dynamic and interactive conditions aiming at developing cooperative discovery of knowledge through collective work, present obvious advantages in comparison to the modes of individualistic learning of the past decedes (Johnson \& Johnson, 1994; Kagan, 1994; Slavin, 
1991; Shultz, 1989.). Papert (1991) suggested that we should not use the new learning tools to teach in the same ways as in the past. All the parts of the system have to follow the procedure to the new era.

Many questions of philosophical, epistemological, educational and sociological direction have been formulated with respect to educational and learning problems and also to the emergence of possible dangers from the introduction and use of technology in education on the other (Apple, 1991. Cuban, 1986. Hawkridge, 1990. Papert, 1991. White, 1987).

According to Bruner (1966) and many other scientists a prerequisite for the development of the human brain is the knowledge of usage and administration of all those social tools, instruments, technology in general, which can promote the expression and creative transformation of human abilities and skills.

Various arts and sciences can be combined in school for interdisciplinary and inter-thematic purposes. In the teaching language, for example, on the basis of literacy theory as a methodological approach, technology can be applied in various ways.

Projects can be technologically supported during all stages of their design and implementation, in almost from age 0 ! The incorporation of the evaluation process, with the appropriate way to be done and the correct timely evaluative feedback, make the individualized learning a big achievement. Evaluation therefore becomes part of the learning process and is used for designing further work (Alexandratos \& Rapti, 2004).

Educators have the chance to become more active and creative when designing teaching projects, and can experiment with innovative teaching initiatives in a multi cooperative framework. All this means that they can share these initiatives with their colleagues, and can increase the probability of the improvement of these initiatives as well as can contribute to the educators' own professional development. Besides, education is a common place for many of us.

\section{To be or not to be: towards an evolution}

School, both as an environment and as a holistic context, has the obligation to take social changes that take place in the wider society into account and to adapt to them accordingly. This seems to be the right way to prepare the members of the new generation to come and begin to face the future conditions in which they will live, create and be critical citizens.

Teaching with the use of computers takes place in a laboratory environment, most of the times. This gives the educator the chance to deal with learning difficulties, in almost a safe way. They can also cultivate self-knowledge, develop democratic and multi-cultural exchange, and promote solidarity and empathy among many different learning groups. In such a way, the communication structures of a classroom change: they acquire greater width and extended skills. For the classic teacher and any kind of educator the benefits are not negligible, as any of them has the opportunity to work together with students, following in reality their own personal style and development (Hay, Guzdial, Jackson, Boyle, \& Soloway, 1994. Lebrun, 1999. Mitra, 2000).

The interactive board is under teacher's control and the use of the electronic material can be done without losing contact with the class (Solvie, 2001). During this new procedure, the educator is called to redefine the lesson's scope and approach and can make a step to improve with the use of new technologies.

The educators themselves report that technology in the classroom competes with all the other technological tools that exist in children's lives, in a professional and pedagogical manner (Miller et al., 2005). These new differentiated roles for the student and the teacher alike are obviously more demanding, but at the same time more creative and more specialized than there were in the past (Hershkowitz \& Schwartz, 1999. Noss \& Hoyles, 1996). 


\section{Percentage of individuals who judge their computer skills would be sufficient if they were to apply for a new job within a year, 2013}

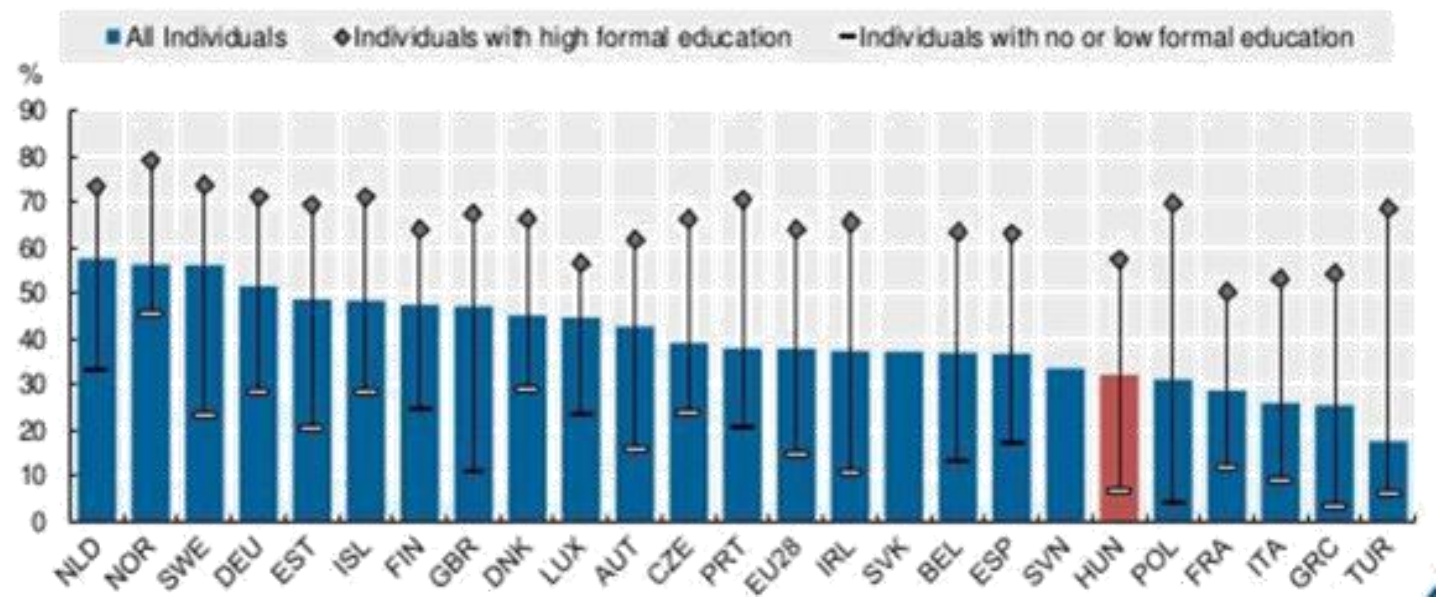

Figure 3. Some indicative numbers on efficiency (Source: OECD computations based on Eurostat, Information Society statistics, May 2014)

\section{The core value of the visual learning procedure}

The use of visual literacy ideas and strategies to enhance verbal learning is so important (Flattley, 1998; Sinatra, 1986) since visual literacy precedes verbal literacy in human developmen. So, it is the basic literacy in the thought processes that is the foundation for reading and writing. Berger (1972) explains, "Seeing comes before words. The child looks and recognizes before it can speak"

The Dale Cone of Experience model is based on the concept that learning is about going from the concrete to the abstract; visual symbols are nonverbal representations that precede verbal symbols (Sinatra, 1986).

The way from action progress to activities of observation are followed by abstract representations, a process that facilitates reconceptualization and understanding of the experience even before can be described with words. Pictures or illustrations are analogs of experience and are only one step removed from actual events. Can be visual representations able to capture and communicate the concrete experience in many various ways.

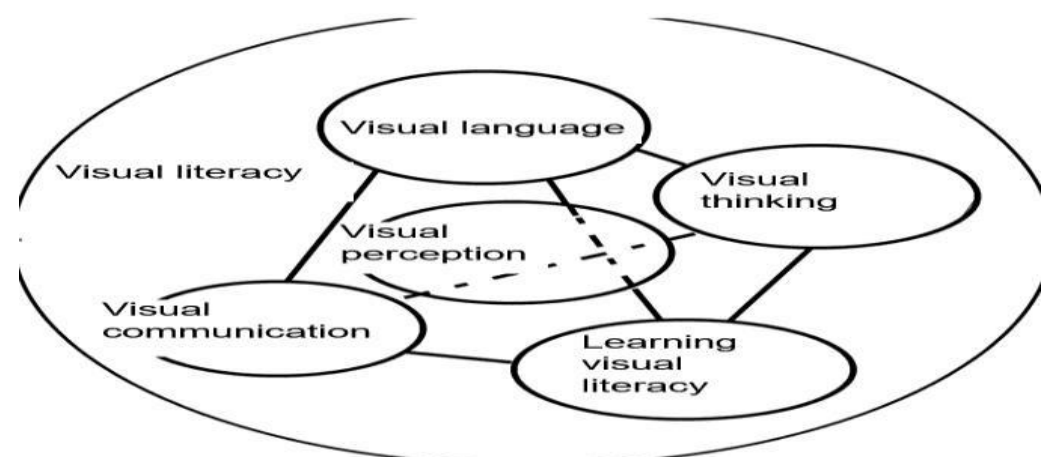

Figure 4. The visual learning model, a general approach (Source: Internet search)

So, we are creating a hybrid system, learner centric, using image as language and a language more accurate than ever before.

The use of visuals in education, although consistently shown to add value in the learning procedure, must be carefully planned. The use of visuals can encourage thoughtful analysis of the underlying meaning and can for sure interfere with the intent of the lesson (Sherry, 1996). 
Dwyer (Williams \& Dwyer, 1999) suggests that visuals must be properly used in the educational setting since visualization alone does not function to maximize student achievement. The study by Williams and Dwyer of the effect of metaphoric strategies in the achievement of the objectives of learning indicates that the use of verbal and visual metaphors to complement visualized instruction is not always an effective instructional strategy.

For example, visual organizers that incorporate illustrations and text to depict patterns of concepts and ideas serve as organizational frameworks to promote critical thinking and learning (Tarquin \& Walker, 1997).

Frameworks assist learners in visualizing how their ideas may be related to prior knowledge, subordinate ideas, and information from many other sources. Story maps that can be depicted as vertical or horizontal flow maps, diagrams that provide useful information are some use full tools to be used.

\section{Conclusion}

"A good picture is equivalent to a good deed" (Van Gogh, http://quoteworld.eilc.org/ search.cgi). Although teachers and learners are on the same side, the discussion of the big picture involves change of roles while learners become teachers too.

The construction of a hybrid educational system when image and words can give a way to clear answers and informed decisions can be relieved is the small contribution a to big universe.

All of us can understand what the fire in Amazon means when we see it but if we add some words on it seems more complicated sometimes.

\section{Acknowledgement}

This paper is part of my $\mathrm{PhD}$ thesis on "Visual Literacy and its impacts on creativity and critical thinking" supervised by Ass. Professor Ioannis Kolaxizis, which is about to be defended at the end of 2021.

\section{References}

Alexandratos \& Rapti, 2004. The contribution of New Technologies in collaboration teaching, National Conference, University of Athens, vol. B' p. 440-448, Athens.

Apple, M. W. (1991). The new technology: Is it part of the solution or part of the problem in education? Computers in the Schools, 8, 59-81.

Benson, P. J. (1997). Problems in picturing text: A study of visual/verbal problem solving. Technical Communication Quarterly, 6(2), 141-160. from EBSCOhost database (Professional Development Collection).

Berger, J. (1972). Ways of seeing. London: Britain Broadcasting Corp.

Bruner, J. S. (1966). Toward of theory of instruction. Cambridge, MA: The Belknap Press of Harvard University Press.

Cuban, L. (1986). Teachers and machines: The classroom use of technology since 1920. New York: Teachers College Press.

Flattley, R. (1998). Visual literacy.Pima Community College, Downtown Campus Psychology Department Web site: http://dtc.pima.edu/psychology/Visual_Literacy.html

Hawkins, J., \& Blakeslee, S. (1996). On intelligence. New York: Henry Holt and Company.

Hawkridge, D. (1990). Who needs computers in schools and why? Computers and Education, $15,1-6$. 
Hay, E., Guzdial, M., Jackson, S., Boyle, A., \& Soloway, E. (1994). Students as multimedia composers. Computer Education, 23, 301-307.

Hershkowitz, R., \& Schwartz, B. B. (1999). Reflective processes in a technology-based mathematics classroom. Cognition and Instruction, 17, 65-91.

Johnson, D. W., \& Johnson, R. T. (1994). Learning together and alone: Cooperative, com

petitive and individualistic learning (4th ed.). Boston: Allyn \& Bacon.

Lebrun, M. (1999). Des technologies pour enseigner et apprendre. Paris/Bruxelles: De Boeck Universite.

Miller, D. J., Glover, D., \& Averis, D. (2005). Developing pedagogic skills for the use of the interactive whiteboard in mathematics. British EducationalResearch Association, Glamorgan.

Mitra, J. (2000). Creating and using multimedia applications. In M. Leask \& Meadows (Eds.), Teaching and learning with ICT (pp. 144-162). London/New York: Routledge Falmer.

Noss, R., \& Hoyles, C. (1996). Windows on mathematical meanings: Learning cultures and computers. Boston: Kluwer.

Papert, S. (1991). Situating constructionism. In I. Harel, I. \& S. Papert, S. (Eds.), Constructionism (pp. 133-142). Norwood, NJ: Ablex Publishing.

Shultz, J. L. (1989). Cooperative learning: Refining the process. Educational Leadership, 47, 43-45. Slavin, R. E. (1991). Synthesis of research of cooperative learning. Educational Leadership, 48, 71-77.

Sinatra, R. (1986). Visual literacy connections to thinking, reading and writing. Springfield, IL: Charles C. Thomas.

Tarquin, P., \& Walker, S. (1997). Creating success in the classroom! Visual organizers and how to use them. Englewood, CO: Teacher Ideas Press.

US Congress, Office of Technology Assessment. (1988). Power on! New tools for teaching and learning. Washington DC.

West, T. G. (1997). In the mind's eye. Amherst, NY: Prometheus Books.

White, M. A. (1987). What curriculum for the information age? Hillsdale, NJ:Lawrence Erlbaum.

Williams, V. S., \& Dwyer, F. (1999). Effect of metaphoric (visual/verbal) strategies in facilitating student achievement of different educational objectives. International Journalof Instructional Media, 26(2), 205-211. EBSCOhost database (Academic Search Elite). 